\title{
Konsep Diri dengan Kejadian Depresi pada Pasien Gagal Ginjal Kronik yang Menjalani Hemodialisa di RSUD Panembahan Senopati Bantul
}

\author{
Eka Nurul Fitriyani ${ }^{1}$, Sri Arini Winarti ${ }^{2}$ Sunarsih $^{3}$ \\ 1,2,3 Sekolah Tinggi IImu Kesehatan Alma Ata Yogyakarta \\ Jalan Ringroad Barat Daya No 1 Tamantirto, Kasihan, Bantul, Yogyakarta
}

\begin{abstract}
Abstrak
Gagal ginjal merupakan masalah kesehatan masyarakat yang semakin meningkat setiap tahunnya. Penderita gagal ginjal kronik yang selalu ketergantungan pada mesin dialisa seumur hidup akan mengakibatkan terjadinya perubahan dalam kehidupan pasien seperti perubahan biologis, psikologis, sosial dan spiritual. Kondisi seperti ini akan menyebabkan pasien memiliki konsep diri negatif seperti sifat rendah diri, takut,cemas, bahkan depresi. Tujuan penelitian untuk mengetahui hubungan antara konsep diri dengan kejadian depresi pada pasien gagal ginjal kronik yang menjalani hemodialisa di RSUD Panembahan Senopati Bantul. Penelitian ini merupakan penelitian deskriptif analitik dengan pendekatan cross sectional. Sampel yang digunakan dalam penelitian ini sebanyak 61 responden, dengan teknik accidental sampling. Data dikumpulkan dengan menggunakan kuesioner dan kemudian dianalisis menggunakan Chi-square. Hasil penelitian konsep diri pasien gagal ginjal kronik yang menjalani hemodialisa sebagian besar memiliki konsep diri negatif (67,2\%), kejadian depresi mayoritas pasien gagal ginjal kronik yang menjalani hemodialisa mengalami depresi sebesar (82\%). Hasil uji Chi-square didapatkan nilai p-value 0,02 (<0,05). Kesimpulan penelitian terdapat hubungan antara konsep diri dengan kejadian depresi pada pasien gagal ginjal kronik yang menjalani hemodialisa.
\end{abstract}

Kata Kunci: gagal ginjal kronik, konsep diri, kejadian depresi

\section{Self-Concept with Depression in Patients with Renal Failure who Undergo Hemodialysis at RSUD Panembahan Senopati Bantul}

\begin{abstract}
Kidney failure is a public health problem that is increasing every year. Patients with chronic renal failure always depended on dialysis machines, it may result a changes in their life as biological, psychological social, and spiritual changes. This condition may cause patient has negative self-concept such a nature inferiority, fear, anxious, even depression. The purpose of this study was to know relationship between self-concept and depression in patients who undergo hemodialysis at RSUD Panembahan Senopati Bantul. The study design was descriptive analytic with cross sectional. The samples were 61 respondents, it was selected by accidental sampling. The study instrument used questionnaire and analysis used was chi-square. The results showed that self-concept of patients with chronic renal was $67.2 \%$ negative, incidence of depression among patients who undergo hemodialysis was $82 \%$. The chi-square test results obtained value of $p 0.02(<0.05)$. In conclusion, there was a relationship between self-concept and depression in patients with chronic renal failure who undergo hemodialysis.
\end{abstract}

Keywords: chronic renal failure, self concept, the incidence of depression

Info Artikel:

Artikel dikirim pada 7 Oktober 2014

Artikel diterima pada 7 Oktober 2014 


\section{PENDAHULUAN}

Gagal ginjal kronik merupakan masalah kesehatan masyarakat yang cukup serius, selain itu biaya perawatan dan pengobatan cukup mahal. Prevalensi penderita gagal ginjal kronik di Amerika Serikat pada tahun 2002 sekitar 345.000 orang. Angka kejadian gagal ginjal pada tahun 2010 menjadi 660.000 orang. Jumlah pasien gagal ginjal kronik pada tahun 2007 di Indonesia mencapai 2.148 orang, kemudian tahun 2008 meningkat menjadi 2.260 orang. Menurut data dari Penefri (Persatuan Nefrologi Indonesia), diperkirakan ada 70.000 penderita ginjal di Indonesia, namun yang terdeteksi menderita gagal ginjal tahap terminasi dari mereka yang menjalani hemodialisa hanya sekitar 4.000 sampai 5.000 saja(1). Dialisis sebagai pengobatan pengganti untuk gagal ginjal kronik dibagi atas dua yaitu dialisis peritoneal dan hemodialisa. Di Indonesia sendiri prevalens rate penderita End-Stage Renal Disease yang menjalani hemodialisa pada tahun 2006 sebesar 23,4/1.000.000 penduduk(2).

Pada penderita gagal ginjal kronik, kondisi tubuh yang melemah dan ketergantungan pada mesin-mesin dialisis sepanjang hidupnya akan menyebabkan penderita dituntut untuk dapat melakukan penyesuaian diri secara terus menerus sepanjang hidupnya, keadaan tersebut dapat menimbulkan perasaan tertekan dan tidak nyaman bahkan dapat berujung pada munculnya gangguan mental seperti depresi pada penderita(3).

Pasien gagal ginjal kronik selalu ketergantungan pada mesin dialisa atau harus melakukan hemodialisa seumur hidup, hal ini mengakibatkan terjadinya perubahan dalam kehidupan pasien, di antaranya perubahan biologis, psikologis, sosial, dan spiritual. Efek fisik dapat menimbulkan kelelahan, sakit kepala dan biaya yang dikeluarkan cukup mahal, kondisi seperti ini akan menyebabkan pasien menjadi pesimis dan beranggapan hidup tidak akan bertahan lama, sebagai kepala keluarga pasien akan kehilangan sumber pendapatanya karena tidak mampu bekerja seperti biasanya, sehingga tidak sedikit pasien yang menjalani hemodialisa banyak yang merasa putus asa dan ingin menghentikan pengobatanya serta melakukan tindakan bunuh diri(4).

Konsep diri adalah cara individu yang melihat pribadinya secara utuh menyangkut emosi, fisik, intelektual, sosial dan spiritual(5). Menurut Agustiani mengatakan bahwa konsep diri berpengaruh kuat pada tingkah laku seseorang(6). Konsep diri yang positif akan menghasilkan bentuk-bentuk tingkah laku yang positif pula. Tingkah laku yang positif akan mengurangi sifat rendah diri, takut, kecemasan yang berlebihan, dan sebagainya.
Lubis mengungkapkan bahwa berkurangnya konsep diri merupakan salah satu gejala sosial yang dialami oleh penderita depresi(7). Prevalensi konsep diri negatif pada pasien gagal ginjal kronik yang menjalani hemodialisa yaitu sebesar $78,33 \%(3)$.

Berdasarkan hasil studi pendahuluan di unit Hemodialisa RSUD Panembahan Senopati Bantul, dari bulan desember 2013 hingga januari 2014 tercatat jumlah penderita gagal ginjal kronik yang rutin menjalani hemododialisa sebanyak 156 orang. Hasil wawancara penulis kepada 11 pasien yang akan menjalani hemodialisa di unit Hemodialisa Panembahan Senopati bantul, dari 11 pasien ditemukan 2 pasien cenderung memiliki konsep diri negatif. Ditandai dengan seringnya merasa kecewa, menolak untuk menerima perubahan dalam dirinya, dan memberikan penilaian yang rendah pada kemampuan diri sendiri. Sementara itu ditemukan 4 pasien memiliki kecenderungan mengalami depresi, seperti memiliki perasaan tidak berharga, lebih suka berdiam diri di rumah dan merasa tidak berdaya.

Tujuan penelitian untuk mengetahui adakah hubungan antara konsep diri dengan kejadian depresi pada pasien gagal ginjal kronik yang menjalani hemodialisa di RSUD Panembahan Senopati Bantul.

\section{BAHAN DAN METODE}

Jenis penelitian yang digunakan adalah penelitian deskriptif dengan rancangan penelitian Cross Sectional. Penelitian ini dilakukan di RSUD Panembahan Senopati Bantul pada 26 Juni-3 Juli 2014. Populasi dalam penelitian ini adalah seluruh pasien yang sedang menjalani hemodialisa di Unit Hemodialisa RSUD Panembahan Senopati Bantul. Jumlah populasi penelitian ini adalah 156 orang. Teknik pengambilan sampel adalah dengan cara Acidental Sampling. Kriteria Inklusi: pasien rutin yang menjalani hemodialisa, pasien dalam kondisi stabil dan dapat berkomunikasi dengan baik, pasien bersedia menjadi responden. Kriteria Eksklusi: Pasien yang tidak kooperatif dan tidak mau menjadi responden penelitian, pasien mengalami gangguan kesadaran. Dalam penelitian ini besar sampel 61 responden diperoleh berdasarkan rumus Solvin(8). Instrument dalam penelitian ini adalah kuesioner depresi dan konsep diri. Kuesioner telah diuji validitas dan reliabilitas. Kuesioner depresi dilakukan uji validitas pada tanggal 24 November 2010 pada 30 pasien di unit layanan rawat jalan pokdisus HIVIAIDS RS Cipto Mangunkusumo dengan kriteria sampel yang sudah ditentukan. Hasil uji validitas dan reabilitas ialah: kuesioner berjumlah 20 item pertanyaan, dan didapatkan semua item valid dengan nilai koefisien validitas $=0,3(r=0,310-0,843)$ dan instrument reliabel 
dengan koefisien reabilitas Alpha Cronbach 0,892. Kuesioner konsep diri dilakukan uji validitas pada bulan Januari 2004 pada 15 responden di unit hemodialisa RS Dr. Sardjito. Hasil uji validitas mengenai konsep diri dengan 20 item pertanyaan didapatkan hasil $0,515-$ 0,886 dan instrumen reabilitas dengan nilai r 0,954 .

\section{HASIL DAN BAHASAN}

\section{Karakteristik Responden}

Responden dalam penelitian adalah pasien gagal ginjal kronik yang menjalani hemodialisa di RSUD Panembahan Senopati bantul yang memenuhi criteria penelitian. Karakteristik responden meliputi umur, jenis kelamin, sosial ekonomi, status perkawinan yang disajikan dalam Tabel 1.

Tabel 1. Distribusi Frekuensi Karakteristik Responden di Unit Hemodialisa RSUD Panembahan Senopati Bantul

\begin{tabular}{lcc}
\hline \multicolumn{1}{c}{ Karakteristik } & f & \% \\
\hline Umur (WHO) & & \\
18-39 tahun & 15 & 24,6 \\
40-65 tahun & 43 & 70,5 \\
> 65 tahun & 3 & 4,9 \\
Jenis kelamin & & \\
Laki-laki & 29 & 47,5 \\
Perempuan & 32 & 52,5 \\
Sosial ekonomi & & \\
>Rp. 1.125.500,00 & 29 & 47,5 \\
SRp. 1.125.500,00 & 32 & 52,5 \\
Status perkawinan & & \\
Menikah & 50 & 82,0 \\
Belum menikah & 3 & 4,9 \\
Janda/duda & 8 & 13,1 \\
$\quad$ Total & 61 & 100,0 \\
\hline
\end{tabular}

Sumber: Data Primer 2014

Berdasarkan Tabel 4 di atas menunjukan bahwa karakteristik responden kelompok umur yang paling banyak berumur 40-65 tahun, yaitu sebanyak 43 orang $(70,5 \%)$, berdasarkan jenis kelamin yaitu sebagian besar berjenis kelamin perempuan sebanyak 32 orang $(52,5 \%)$, berdasarkan sosial ekonomi yaitu sebagian besar responden berstatus sosial ekonomi rendah sebanyak 32 orang (52,5\%), berdasarkan status perkawinan yaitu sebagian besar berstatus menikah yaitu sebanyak 50 orang $(82,0 \%)$.

\section{Hasil Pengolahan Data}

Konsep diri yang dimaksud adalah berupa gambaran diri, ideal diri, identitas diri, peran diri, dan harga diri pasien gagal ginjal kronik yang menjalani
Tabel 2. Distribusi Frekuensi Variabel Pasien Gagal Ginjal Kronik di Unit Hemodialisa RSUD Panembahan Senopati Bantul

\begin{tabular}{ccc}
\hline Variabel & f & \% \\
\hline Konsep diri & & \\
Negatif & 41 & 67,2 \\
Positif & 20 & 32,8 \\
Kejadian depresi & & \\
Depresi & 50 & 82,0 \\
Tidak depresi & 11 & 18,0 \\
Total & 61 & 100,0 \\
\hline
\end{tabular}

Sumber: Data Primer 2014

hemodialisa. Penggolongan konsep diri ini digolongkan menjadi 2 kategori yaitu negatif dan positif.

Berdasarkan Tabel 2 menunjukan bahwa menurut sebagian besar responden memiliki konsep diri negatif yaitu sebanyak 41 orang $(67,2 \%)$ dan pasien yang menjalani hemodialisa mengalami depresi yaitu sebanyak 50 orang (82\%).

Kejadian depresi diukur dengan menggunakan kuesioner The Center For Epidemiologycal Studies Depression Scale (CES-D), instrument ini lebih mencakup gejala-gejala dasar depresi yang sering diderita pasien dengan penyakit kronik yang dialami hampir setiap hari selama 1 minggu atau lebih(9).

Hasil ini menunjukan bahwa sebagian besar responden gagal ginjal kronik yang menjalani hemodialisa memiliki konsep diri negatif. Penelitian Fatimah juga menyebutkan bahwa sebagian besar responden gagal ginjal kronik yang menjalani hemodialisa memiliki konsep diri negatif yaitu $28,1 \%(10)$.

Penderita gagal ginjal kronik yang memiliki konsep diri negatif akan cenderung bersikap pesimistik terhadap keadaan yang dialaminya, membenci dirinya, tidak mampu menghargai dan menerima keadaan dirinya, selalu berfikir negatif, menutup diri, dan menghindar ketika berinteraksi dengan orang lain(3).

Menurut Delaune \& Ladner menyebutkan bahwa konsep diri (Persepsi individu terhadap dirinya) mempengaruhi aspek dalam kehidupan termasuk hubungan, kemampuan fungsional dan status kesehatan(11). Setiap orang memiliki pandangan yang positif dan negatif terhadap diri pada aspek fisik, emosional, intelektual, dan dimensi fungsional yang akan berubah setiap waktu tergantung pada situasi. Sedangkan menurut Kozier, dkk penyakit dan trauma juga bisa mempengaruhi konsep diri seseorang terhadap stresor seperti penyakit dan perubahan yang berhubungan dengan penuaan akan berbeda, penerimaan, menolak, menarik diri dan depresi adalah reaksi yang sering terjadi(12).

Hasil penelitian didapatkan hasil bahwa angka kejadian depresi sebanyak 50 orang (82\%). Penelitian 
yang dilakukan Prasetya menunjukan hasil bahwa depresi merupakan masalah yang sering terjadi pada pasien gagal ginjal kronik yang menjalani hemodialisa yaitu sebesar $(64,8 \%)(13)$. Hasil ini sejalan dengan penelitian Chelliah yang menyebutkan bahwa mayoritas pasien yang menjalani hemodialisa mengalami depresi yaitu sebesar 19 orang (52,8\%)(14). Penelitian Rustiana juga menyatakan bahwa 62 responden yang menjalani hemodialisa dan jumlah responden yang mengalami depresi adalah 24 orang $(35,82 \%)(15)$, hal ini membuktikan bahwa tingginya kejadian depresi pada pasien gagal ginjal kronik disebabkan berbagai faktor yang berhubungan dengan kehidupan sosial, psikologis dan mekanisme biologi. Pengobatan dialisis secara rutin dan perubahan status kesehatan akan berpengaruh terhaadap adanya putus asa, dan menginduksikan kejadian depresi pasien gagal ginjal kronik.

Menurut Hadi salah satu faktor yang berhubungan dengan depresi adalah reaksi terhadap stress dan terlalu lelah dan capek karena menguras tenaga dan fisik(16). Individu dengan hemodialisa jangka panjang sering merasa khawatir akan kondisi sakitnya yang tidak dapat diramalkan dan gangguan dalam mempertahankan pekerjaan, dorongan seksual, depresi akibat sakit yang kronis dan ketakutan menghadapi kematian(17).

\section{Hubungan antara Setiap Karakteristik dengan Kejadian Depresi}

Berdasarkan hasil tabulasi silang antara usia dengan kejadian depresi didapatkan hasil bahwa sebagian besar mengalami depresi pada kelompok umur 40-65 tahun. Hal ini sesuai dengan penelitian yang dilakukan oleh Lukman, dkk dimana kelompok umur yang paling banyak ditemukan sindrom depresi adalah pada kelompok umur 54-62 tahun(18).

Berbeda dengan hasil penelitian yang dilakukan oleh Setiawan dan Novianti tentang faktor-faktor yang berhubungan dengan tingkat depresi pada pasien gagal ginjal kronik, didapatkan hasil bahwa ada hubungan yang signifikan antara usia responden dengan depresi, hai ini dibuktikan bahwa pada kelompok umur $>50$ tahun mengalami tingkat depresi yang tinggi(19). Sejalan dengan Nevid, dkk yang menyatakan depresi paling banyak pada pasien yang sudah lanjut usia, ini dikarenakan pada lansia kadang ada kecenderungan mengingkari bahwa ia punya masalah karena mungkin dia merasa sudah tidak setegar dulu. Depresi pada lanjut usia juga disebabkan karena yang bersangkutan menderita beberapa penyakit fisik sehingga tumpang tindih, lalu timbul depresi(20).

Hasil tabulasi silang antara jenis kelamin dengan depresi didapatkan hasil bahwa yang paling banyak menderita depresi adalah berjenis kelamin perempuan. Hasil ini sama dengan hasil penelitian Wijaya bahwa tingkat depresi lebih banyak terjadi pada perempuan dibandingkan pada laki-laki(21).

Penelitian ini tidak sejalan dengan hasil penelitian Rustiana yang menyatakan bahwa tingkat depresi itu terjadi paling banyak pada laki-laki, pendapat Ruli juga menyatakan bahwa pria memang lebih rentan dengan penyakit gagal ginjal kronik dari pada perempuan, sedangkan dari depresi perempaun lebih mudah terserang depresi karena wanita lebih sering mengakui adanya depresi dibandingkan lakilaki dan dokter lebih dapat mengenali depresi pada perempuan $(22,23)$.

Tabel 3. Tabulasi Silang dan Uji Chi-Square antara Setiap Karakteristik dengan Kejadian Depresi

\begin{tabular}{|c|c|c|c|c|c|c|c|c|}
\hline \multirow{3}{*}{ Karakteristik } & \multicolumn{6}{|c|}{ Kejadian depresi } & \multirow{3}{*}{$\chi^{2}$} & \multirow{3}{*}{ p-value } \\
\hline & \multicolumn{2}{|c|}{ Depresi } & \multicolumn{2}{|c|}{ Tidak depresi } & \multicolumn{2}{|c|}{ Total } & & \\
\hline & $f$ & $\%$ & $f$ & $\%$ & $f$ & $\%$ & & \\
\hline \multicolumn{9}{|l|}{ Umur (WHO) } \\
\hline 18-39 tahun & 14 & 23,0 & 1 & 1,6 & 15 & 24,6 & 2,030 & 0,362 \\
\hline 40-65 tahun & 34 & 55,7 & 9 & 14,8 & 43 & 70,5 & & \\
\hline$>65$ tahun & 2 & 3,3 & 1 & 1,6 & 3 & 4,9 & & \\
\hline \multicolumn{9}{|l|}{ Jenis kelamin } \\
\hline Laki-laki & 25 & 41,0 & 4 & 6,6 & 29 & 47,5 & 0,672 & 0,412 \\
\hline Perempuan & 25 & 41,0 & 7 & 11,5 & 32 & 52,5 & & \\
\hline \multicolumn{9}{|l|}{ Sosial ekonomi } \\
\hline >Rp. 1.125.500,00 & 18 & 29,5 & 11 & 18,0 & 29 & 47,5 & 14,808 & 0,000 \\
\hline$<$ Rp. $1.125 .500,00$ & 32 & 52,5 & 0 & 0 & 32 & 52,5 & & \\
\hline \multicolumn{9}{|l|}{ Status perkawinan } \\
\hline Menikah & 40 & 65,6 & 10 & 16,4 & 50 & 82,0 & 0,957 & 0,620 \\
\hline Belum menikah & 3 & 4,9 & 0 & 0 & 3 & 4,9 & & \\
\hline Janda/duda & 7 & 11,5 & 1 & 1,6 & 8 & 13,1 & & \\
\hline Total & 50 & 82,0 & 11 & 18,0 & 61 & 100,0 & & \\
\hline
\end{tabular}

Sumber: Data Primer 2014 
Berdasarkan hasil tabulasi silang didapatkan hasil bahwa kejadian depresi lebih banyak terjadi pada kelompok sudah menikah. Hasil ini tidak sesuai dengan penelitian Rustiana yang menyatakan bahwa ada hubungan antara depresi dengan status perkawinan(22). Sadock \& Sadock menyatakan bahwa pada umumnya gangguan depresi berat terjadi paling sering pada orang yang tidak memiliki hubungan interpersonal yang erat, pasangan bercerai, atau berpisah(24).

Berdasarkan hasil tabulasi silang didapatkan hasil bahwa kejadian depresi lebih banyak terjadi pada kelompok ekonomi rendah. Menurut Nevid, dkk Orang dengan taraf sosial ekonomi yang lebih rendah memiliki resiko depresi lebih besar dibandingkan mereka dengan taraf yang lebih baik(20).

\section{Hubungan antara Konsep Diri dengan Kejadian Depresi}

Berdasarkan Tabel 4 Tabulasi silang antara konsep diri dengan kejadian depresi diketahui bahwa responden dengan konsep diri negatif dan mengalami depresi yaitu sebanyak 38 orang $(62,3 \%)$, responden dengan konsep diri negatif dan tidak depresi yaitu sebanyak 3 orang $(4,9 \%)$,

Hasil analisis data nilai $p$-value 0,02 , berarti terdapat hubungan antara konsep diri dengan kejadian depresi pada pasien gagal ginjal kronik yang menjalani hemodialisa di RSUD Panembahan Senopati bantul. Koefisiensi kontigensi sebesar 0,390 yang berarti bahwa hubungan antara konsep diri dengan kejadian depresi pada pasien gagal ginjal kronik yang menjalani hemodialisa dalam kategori sedang.

Penelitian ini sesuai dengan hasil penelitian Azahra bahwa konsep diri dengan dukungan sosial secara bersama-sama memiliki peran yang sangat signifikan, berdasarkan hal ini dapat disimpulkan bahwa konsep diri dan dukungan sosial secara bersama-sama berperan dan mempengaruhi terjadinya depresi(3). Seperti pendapat yang dikemukakan oleh Lubis mengungkapkan bahwa depresi dipengaruhi oleh beberapa faktor diantaranya yaitu faktor psikologis yang meliputi kepribadian seperti adanya konsep diri yang rendah (negatif), sikap pesimis, tipe kepribadian dan adanya pengaruh yang berasal dari lingkungan keluarga seperti ada atau tidaknya dukungan, dorongan maupun bantuan dari pihak keluarga(7).

Sebuah penelitian lain yang dilakukan Nisak, dkk tentang status konsep diri dengan kejadian depresi menemukan bahwa ada hubungan antara status konsep diri dengan kejadian depresi(25). Penelitian ini juga didukung oleh hasil penelitian Beck \& Alford bahwa ada hubungan yang signifikan antara konsep diri dengan tingkat depresi. Dari penelitian ini diketahui bahwa penderita depresi cenderung memberikan poin rendah pada dirinya dalam penerimaan sosial dan memberikan poin yang tinggi dalam poin penolakan sosial. Beck \& Alford menyimpulkan bahwa konsep diri ditemukan lebih rendah pada penderita depresi jika dibandingkan dengan mereka yang tidak mengalami depresi(26). Penelitian lain yang dilakukan oleh Sowislo menunjukan adanya hubungan yang kuat antara harga diri dan depresi. Secara khusus Sowislo mengungkapkan bahwa penurunan harga diri adalah prediksi peningkatan depresi(27).

Faisal menambahkan bahwa konflik dari diri sendiri yang tidak terselesaikan, pemikiran pesimis, perasaan bersalah, evaluasi diri negatif, dan harga diri rendah merupakan faktor psikososial yang mencetuskan kejadian depresi. Keeratan hubungan antara konsep diri dengan kejadian depresi pada pasien gagal ginjal kronik yang menjalani hemodialisa dalam kategori sedang hal ini dikarenakan tidak hanya konsep diri yang menjadi faktor utama penyebab depresi, namun ada faktor-faktor lain yang dapat meyebabkan depresi yaitu dari faktor psikososial, faktor religius, faktor sosial ekonomi, dan stres dalam kehidupan pasien(28).

\section{SIMPULAN DAN SARAN}

Berdasarkan hasil penelitian dan analisa data yang telah dilakukan selama penelitian dapat disimpulkan bahwa konsep diri pada pasien gagal ginjal kronik yang menjalani hemodialisa rata-rata memiliki konsep diri negatif. Pasien gagal ginjal kronik yang menjalani hemodialisa sebagian besar mengalami depresi. Hasil penelitian mengenai variabel konsep diri pasien henodialisa dengan kejadian depresi terdapat hubungan dalam kategori sedang. Saran bagi pasien gagal ginjal kronik agar memiliki konsep diri positif dan pihak keluarga memberikan dukungan.

Tabel 4. Tabulasi Silang dan Uji Chi-Square antara Konsep Diri dengan Kejadian Depresi

\begin{tabular}{|c|c|c|c|c|c|c|c|c|c|}
\hline \multirow{3}{*}{$\begin{array}{c}\text { Konsep } \\
\text { diri }\end{array}$} & \multicolumn{6}{|c|}{ Kejadian depresi } & \multirow{3}{*}{$\chi^{2}$} & \multirow{3}{*}{$p$-value } & \multirow{3}{*}{$\begin{array}{l}\text { Koef. } \\
\text { Cont }\end{array}$} \\
\hline & \multicolumn{2}{|c|}{ Depresi } & \multicolumn{2}{|c|}{ Tidak depresi } & \multicolumn{2}{|c|}{ Total } & & & \\
\hline & $f$ & $\%$ & $f$ & $\%$ & $f$ & $\%$ & & & \\
\hline Negatif & 38 & 62,3 & 3 & 4,9 & 41 & 67,2 & 9,715 & 0,002 & 0,390 \\
\hline Positif & 12 & 19,7 & 8 & 13,1 & 20 & 32,8 & & & \\
\hline Total & 50 & 82,0 & 11 & 18,0 & 61 & 100,0 & & & \\
\hline
\end{tabular}

Sumber: Data Primer 2014 


\section{RUJUKAN}

1. Hadibroto A. Gagal ginjal. Jakarta: PT. Gramedia Pustaka Utama; 2007.

2. Siallagan $\mathrm{H}$, Rasmaliah, Jemani. Karakteristik Penderita Gagal Ginjal Kronik yang Dirawat Inap di RS Martha Friska Medan. Jurnal Departemen Epidemiologi: Fakultas Kesehatan Masyarakat Universitas Sumatra Utara; 2011.

3. Azahra M. Peran Konsep Diri dan Dukungan Sosial Terhadap Depresi pada Penderita Gagal Ginjal Yang Menjalani Terapi Hemodialisa. Jurnal Universitas Ahmad Dahlan Yogyakarta. 2013;2(1).

4. Caninsti R. Gambaran Kecemasan dan Depresi pada Penderita Gagal Ginjal Kronik yang Menjalani Terapi Hemodialisa. Jurnal Psikologi Universitas Indonesia; 2007.

5. Sunaryo. Psikologi untuk Keperawatan. Jakarta: EGC; 2004.

6. Agustian. Psikologi Perkembangan: pendekatan Etiologi kaitanya dengan Konsep Diri dan Penyesuain diri pada Remaja. Jakarta: Refika Aditama; 2006.

7. Lubis N. Depresi dari Tinjauan Psikologis. Jakarta: Kencana Prenada Media Group; 2009.

8. Nursalam. Konsep dan Penerapan Metodologi Penelitian IImu Keperawatan: Pedoman Skripsi, Tesis, dan Instrumen Penelitian Keperawatan. 1st ed. Jakarta: Salemba Medika; 2003.

9. Kusuma H. Hubungan antara depresi dan dukungan keluarga dengan kualitas hidup pasien HIVIAIDS yang menjalani Perawatan di RSUPN Cipto Mangunkusumo Jakarta. Universitas Indonesia Fakultas IImu Keperawatan Kekhususan Keperawatan Medikal Bedah. Depok; 2011.

10. Fatimah. Gambaran konsep diri pada pasien gagal ginjal kronik yang menjalani hemodialisa di Instalasi dialisis RSUP Dr. Sardjito. Politeknik Kesehatan Kemenkes Yogyakarta; 2010.

11. Delaune SC, Ladner PK. Fundamental of nursing: Standard and Practice. USA: Thomson Delmar Learning; 2002.

12. Kozier B, Erb G, Bernman, Snyder. Fundamental of Nursing. Concept Proses and Practice. USA: Pearson; 2004.

13. Prasetya K. Pengaruh depresi terhadap kualitas hidup pasien penyakit gagal ginjal kronik yang menjalani hemodialisa. Fakultas Kedokteran Universitas Sumatra Utara; 2010.

14. Chelliah S. Gambaran tingkat depresi dan kualitas hidup pasien penyakit gagal ginjal kronik yang menjalani hemodialisa di RSUP H. Adam Malik Medan. Fakultas Kedokteran Universitas Sumatra Utara Medan; 2011.
15. Rustiana. Gambaran tingkat depresi pada pasien gagal ginjal kronik yang menjalani hemodialisa di RSUD Dr. Soedarso Pontianak. Pontianak: Fakultas Kedokteran Universitas Tanjungpura; 2012.

16. Hadi P. Depresi dan Solusinya. 1st ed. Tugu Publiseher; 2004.

17. Smeltzher SC, Bare BG. Keperawatan Medikal Bedah. Vol. 2. Jakarta: EGC; 2002.

18. Lukman N, Esrom K, Ferdinand. Hubungan tindakan hemodialisa dengan tingkat depresi klien penyakit ginjal kronik di BLU RSUP Prof. Dr. R. D. Kandou manado. jurnal Keperawatan. 2013;1(1).

19. Setiawan R, Novianti K. Faktor-faktor yang berhubungan dengan tingkat depresi pada pasien gagal ginjal kronik yang menjalani tindakan hemodialisa di Ruang Hemodialisa RSUD Dr. Slamet Garut. Jurnal kesehatan Priangan. 2014;1(1).

20. Nevid J, Rathus SA, Greene B. Psikologi Abnormal. 5th ed. jilid 1. Ratri Medyan, editor. Jakarta: Erlangga; 2003.

21. Wijaya A. Kualitas Hidup Pasien Penyakit Gagal Ginjal Kronik yang Menjalani Hemodialisa dan Mengalami Depresi. Jakarta: Fakultas Kedokteran Universitas Indonesia; 2005.

22. Rustiana. Gambaran tingkat depresi pada pasien gagal ginjal kronik yang menjalani hemodialisa di RSUD Dr. Soedarso Pontianak. Pontianak: Fakultas Kedokteran Universitas Tanjungpura; 2012.

23. Ruli. Penatalaksanaan gagal ginjal kronik dan panduan terapi dialisis pusat Informasi IImiah. Fakultas kedokteran Unpad/RS. Dr. Hasan Sadikin; 2008.

24. Sadock BJ, Virginia AS. Buku Ajar Psikiatri Klinis.2nd ed. Jakarta: EGC; 2010.

25. Nisak DK, Reni Z, Yulia I. Hubungan Status Konsep Diri dengan Kejadian Depresi pada Lansia di Balai Pelayanan Sosial Tresna Werdha Khusnul Khotimah Pekanbaru. 2013.

26. Beck AT, Alford BA. Depression: causes and treatment. 2nd ed. Philadelphia: University of Pennsylvania Press; 2009.

27. Sowislo JF, Orth U. Does low self-estreem predict depression and anxienty, A meta-analysis of longitudinal studies. Jurnal of Psychological Buletin Advance. 2012.

28. Faisal MI. Depresi pada penyakit Parkinson. Jurnal Psikiatri Fakultas Kedokteran Universitas Hasanuddin Makasar; 2007. 